\title{
Das Kapital: el secreto de la forma simple de valor
}

Jordi Soler Alomà

Universitat de Barcelona, España 


\title{
Das Kapital: el secreto de la forma simple de valor*
}

Resumen: de todo el corpus marxiano, el primer capítulo de Das Kapital, en el cual se analiza la forma de valor, es, con mucho, el más controvertido, mal interpretado, tergiversado, cuando no directamente obviado... esto no sucede con ninguna otra obra de este autor. La causa de ello es que en dicho capítulo se desvela lo que "se esconde" detrás de lo que damos por supuesto (lo a priori) y, por tanto, cuestiona las bases que rigen nuestra percepción de lo que llamamos "realidad". El objetivo del presente artículo es interpretar, para hacerlo más comprensible, el contenido de dicho capítulo.

Palabras clave: realidad, alienación, sociedad, dinero, valor.

\section{Das Kapital: the secret of the simple form of value}

\begin{abstract}
Marxian corpus, the first chapter of Das Kapital, in which the form of value is analyzed, is by far the most controversial, misinterpreted, distorted, if not directly overlooked... this does not occur with any other work of this author. The reason for this is that this chapter reveals what "lies" beyond what we take for granted (the a priori) and, therefore, questions the bases that govern our perception of what we call "reality". The goal of this article is to interpret the content of this chapter and to make it more understandable.
\end{abstract}

Keywords: reality, alienation, society, money, value.

Fecha de recepción: 5 de febrero de 2019

Fecha de aceptación: 13 de marzo de 2019

Forma de citar (APA): Soler-Alomà, J. (2019). Das Kapital: el secreto de la forma simple de valor. Revista Filosofía UIS, 18(2), doi: 10.18273/revfil.v18n2-2019006

Forma de citar (Harvard): Soler-Alomà, J. (2019). Das Kapital: el secreto de la forma simple de valor. Revista Filosofía UIS, 18(2), 97-124.

Jordi Soler Alomà: español. Doctor en Filosofía, Universitat de Barcelona. Profesor en la Escuela Superior Politécnica del TecnoCampus, España.

Correo electrónico: jordisoleraloma@gmail.com

ORCID: 0000-0001-6693-4859

*Artículo de reflexión derivado de investigación. 


\section{Das Kapital: el secreto de la forma simple de valor}

\section{Exordio}

El objetivo del presente trabajo es acceder a lo que podemos referirnos como al "centro neurálgico" del pensamiento dialéctico de Marx en Das Kapital y vincularlo al concepto de alienación del mismo autor. La obra de Marx ha sido víctima de un tratamiento sui generis, que sería inaceptable para cualquiera de los autores clásicos. Tal incongruencia intelectual respecto de Marx afecta a todo el pensamiento occidental y, muy especialmente, al europeo, que declaró el pensamiento de Marx como oficialmente muerto (i.e. Bad Godesberg, 1959). Otra patología que afecta al estudio del pensamiento de Marx es la no distinción entre lo que constituye propiamente el pensamiento de este autor, y el indeterminado magma especulativo de que se compone el "marxismo" (del cual, como es sabido, el mismo Marx dijo no formar parte).

Sin embargo, aún peor sea, quizás, separar a Marx en distintos personajes en función de los intereses del usuario: el Marx "joven" y el Marx "maduro"; el Marx "feuerbachiano", el Marx "hegeliano", el Marx "economista", el Marx "sociólogo", el Marx "filósofo", el Marx "economista" o el Marx "metodólogo". Solo hay un Marx; un filósofo que no solo estudia la historia de la filosofía, sino (como otrora hicieron las mentes preclaras de Platón o Aristóteles) también estudia la entidad más compleja de la Naturaleza conocida: el ser humano en su integridad, en el sentido más extenso del concepto.

El título del presente trabajo no obedece a que se haya descubierto ningún secreto en el texto de Marx, sino al hecho (que, lamentablemente, se suele eludir) de que él expresa rotundamente que lo más importante y lo esencial de su obra se halla contenido en este capítulo, cuya lectura y asimilación es indispensable para la comprensión cabal de la obra. Es en este contexto donde escribe que "el secreto de toda forma de valor se halla contenido en la forma simple". 


\section{A modo de introducción}

El primer capítulo de El Capital (original alemán: Das Kapital) no es, contra lo que generalmente se cree, un texto intrínsecamente difícil. El escrito está muy bien redactado y es de una claridad deslumbrante. La mayor dificultad para su comprensión radica, principalmente, en la serie de condicionamientos ideológicos que conlleva la alienación, o, dicho de otro modo, el problema no está en la configuración del texto sino en la arquitectura de nuestra mente. El texto exige del lector afrontar dos retos que requieren modificar el comportamiento usual del cerebro común: la capacidad de transcender las apariencias (o, como diría Hegel, transcender la "cosa para nosotros" o lo que sería para Platón "salir de la caverna") y la capacidad de pensar de modo dialéctico (lo que nos aparece como la "realidad", aunque para la percepción sea algo estático —una "congelación" del tiempo; una abstracción del mismo, necesaria para poder entender las cosas), lo que hay siempre es un proceso que, además, en el momento en que entramos a formar parte de él ya esté en marcha, y lo ha estado desde siempre- en el sentido ontológico de dicho concepto.

Algunos autores, tales como Louis Althusser (2010) recomiendan "saltarse" el primer capítulo de Das Kapital por considerarlo "irrelevante" y "hegeliano". Nadie osaría recomendar la no lectura del primer capítulo de las obras de los grandes filósofos. Athusser tampoco leyó la Introducción del primer tomo, donde Marx insiste en que es indispensable la comprensión del primer capítulo. Otro "truco" es recurrir a terceros (divulgaciones, vagas descripciones, etc.); el efecto es el mismo que la propuesta de Althusser, es decir, el soslayo.

El texto que tratamos es lo más profundo que ha escrito Marx, y quizás en toda la historia del pensamiento humano. La lectura y la comprensión de sus sabios parágrafos tienen un exorcismo intelectual; nos liberan de todos los a priori (conceptos ideológicos) que la alienación nos había imbuido, expulsan de nuestra mente todos los estereotipos y prejuicios con los que funcionamos "por defecto", y, por ende, nuestra "alma" queda desnuda ante el "juego" al que "siempre ya estábamos jugando", un juego real cuyas reglas a priori rigen nuestra conducta y nuestra vida, compeliéndonos a comportarnos como meros elementos de un engranaje cuya existencia desconocemos. En otras palabras, la lectura y comprensión del texto nos permite ver la escondida estructura del sistema (sus elementos ocultos, tanto materiales como intelectuales, consuetudinarios o idiosincráticos y las relaciones entre ellos). Por otro lado, la comprensión del significado de los parágrafos de este texto "maldito" exige la renuncia de lo que llamamos " $\mathrm{yo}^{\prime}$; por lo que nos hallamos ante una enorme dificultad psicológica que, naturalmente, provoca rechazo, ya que el texto desafía lo más íntimo que nos constituye como "identidades". 
Marx consideraba iimprescindible! la asimilación del capítulo primero haciendo hincapié en la parte que trata de la mercancía (esencialmente el análisis de la forma simple del valor) como conditio sine qua non para la comprensión cabal de la obra en su conjunto. Es decir, para Marx, Das Kapital constituye un todo inseparable, un edificio cuya puerta de entrada se halla en el primer capítulo. Esto se manifiesta claramente en expresiones tales como "El misterio de toda forma de valor está embutido en esta forma de valor simple. Por eso es su análisis el que presenta la verdadera dificultad" (Marx, 1976, p. 56) ${ }^{1}$, en esta frase Marx nos advierte, tanto de la importancia del asunto que tratamos, como de la dificultad (ideológica) para entenderlo, y frase que por sí misma (y proviniendo del autor de la obra) es suficiente para invitar al lector a dedicar todos los esfuerzos necesarios para comprender, con la inestimable ayuda pedagógica de Marx, este misterio.

Un frívolo observador de la sociedad puede cuestionar la importancia del análisis de la mercancía cuando hay cosas que (desde su punto de vista) son más interesantes. A dicho observador Marx le haría notar un hecho que describe en su obra: la mercancía, en función análoga a la que cumple la célula en el cuerpo humano, es la célula del sistema capitalista (y su estructura ${ }^{2}$ es muy compleja, como se verá en el desarrollo del presente escrito) y porque únicamente conociendo el contenido de la forma de mercancía del producto del trabajo (a través de la comprensión de lo que Marx llama la dialéctica de la mercancía) podemos llegar a conocer lo intrincado del ser del dinero $^{3}$ (qué hay detrás de unos papelitos que llevan un número) y, con ello, cómo funciona (elementos y estructura) la forma de organización capitalista de la sociedad o, brevemente: el sistema capitalista.

Paradójicamente, el elemento más importante del sistema tiene características fantasmagóricas. La mercancía, en realidad, materialmente, no existe: existen cosas para las cuales existen posibles usuarios. Lo que hace que algo (y en la sociedad capitalista prácticamente todo) aparezca bajo la forma de mercancía es nuestra relación alienada con ese "algo", y ese "algo" puede "residir" en cualquier "cosa".

El dinero no es un inocente "medio de cambio" (concepto cuyo significado habrá que acotar); tal como quedará demostrado en esta lectura de Das Kapital, se trata de un elemento fundamental de la arquitectura ideológica ${ }^{4}$ del sistema

\footnotetext{
${ }^{1}$ La paginación hace referencia a la edición OME, aunque por lo acotado del texto se puede seguir con otras ediciones, como la del FCE (Wenceslao Roces) o la de Siglo XXI (Pedro Scaron).

${ }^{2}$ Entendemos por estructura el conjunto de relaciones entre los elementos de un sistema y entre ellos y su entorno. Para buenas definiciones de "estructura" y "sistema" véanse los diccionarios de Filosofía de Ferrater Mora o de Mario Bunge (o, para una visión ampliada, léase la obra de Von Bertalanffy La Teoría General de Sistemas).

${ }^{3}$ Quien crea que esto es una trivialidad (una actitud bastante frecuente) deberá hacer un gran esfuerzo para liberarse de sus prejuicios. El dinero es mucho más de lo que aparenta y, por cierto, no es eso que llevamos en el bolsillo o en la cartera (eso es un simple símbolo del dinero).

${ }^{4}$ La ideología es el "cemento intersubjetivo" que nos obliga a padecer una misma visión, cargada de a prioris, de la realidad; la ideología contiene lo idiosincrásico y lo consuetudinario (ver nota siguiente),
} 
(vid. supra). Nuestro objeto de estudio es un fenómeno que ha adquirido fijeza idiosincrásica ${ }^{5}$ y que, consuetudinariamente ${ }^{6}$, se ha investido de una cualidad análoga a la del tabú (si alguien planteara la abolición del dinero sería considerado un necio). El dinero es "algo" que, sin embargo, posee (o porta) propiedades que se consideran intrínsecamente sociales, y, además, es el mecanismo fundamental de la base ideológica de la alienación $n^{7}$ humana en la forma de organización social cuyos modos de producción y distribución son capitalistas.

La única diferencia entre esclavo y proletario es que el proletario y el trabajador asalariado (proletario "en activo") son considerados libres (cuando la única libertad que tienen es la de "recargarse" para volver al trabajo un día tras otro, para generar más y más plusvalor). Ni las sociedades regidas por dictaduras monárquicas u oligárquicas (el Egipto de los faraones o la América de los campos de algodón), ni la sociedad regida por la oligarquía capitalista (la sociedad moderna y contemporánea) pueden existir sin esclavos.

Al igual que en el mercado de esclavos se establecía el precio de cada esclavo en función de sus características, en el mercado de trabajo el precio del trabajador también es regulado por sus características y, como cualquier otra mercancía, por las relaciones de mercado; el cambio de fuerza de trabajo ${ }^{8}$ por dinero es la compraventa de personas (la fuerza de trabajo es la mercancía-persona). Aunque sea éticamente cuestionable como en la antigua esclavitud. Desde el punto de vista estrictamente mercantil, se trata de un intercambio común y corriente de equivalentes (por eso el concepto de "explotación del hombre por el hombre" es completamente ajeno a la economía liberal, que carece de presupuestos éticos).

Hemos visto que el precio de la fuerza de trabajo se constituye, como el de cualquier otra mercancía, en función de las vicisitudes del mercado, ni más ni menos, como sucedía con los antiguos esclavos, que también eran vendidos en el mercado de esclavos. En la antigua Grecia, sin embargo, el propietario de los esclavos los debía mantener hasta su muerte, mientras que en el capitalismo la esclavitud es cada vez más precaria. Lo que diferencia la compraventa de personas en ambos períodos es que la mercancía fuerza de trabajo, cuando es consumida, produce un monto de valor superior al de su precio de coste (es la única mercancía cuyo consumo produce valor: para toda mercancía, es un

que se adapta al modo de funcionamiento de la sociedad, mezclados con los dogmas de fe y los presupuestos funcionales y fundacionales del sistema.

${ }^{5}$ Idiosincrasia: conjunto de rasgos que configuran un modo común de ver la realidad de un colectivo. ${ }^{6}$ Consuetudinario: dícese de lo que es de costumbre.

${ }^{7}$ Alienación: escisión de la sociedad en (dicho en términos comprensibles) explotadores y explotados unida a la asunción idiosincrásica y consuetudinaria de ese hecho como lo normal.

${ }^{8}$ Concepto fundamental que diferencia el acto (trabajo) de la potencia (fuerza de trabajo) y que ya había sido anticipado por Marx en los Grundrisse der Kritik der politischen Ökonomie en el incipiente concepto de "capacidad de trabajo". 
hecho que su consumo mengua su valor), y en esta creación de valor la persona consumida tiene arte, pero no parte. El proletariado es la gallina de los huevos de oro del capital.

Un aviso para navegantes: el análisis de Marx es genético evolutivo y, consecuentemente, hace abstracción de todo lo que no sea imprescindible para su argumentación científica. En otras palabras: para analizar la "célula" mercancía, hace abstracción de todo lo que nos pudiera distraer del objeto de estudio, del mismo modo que un físico, en la defensa de una hipótesis, abstrae, en su argumentación, de todo lo que no atañe la cosa.

\section{El secreto de la forma de valor}

Las mercancías, en rigor, no existen (ya se ha dicho en la introducción; además, su "existencia material" es uno de los a priori sistémicos). Existen cosas y posibles usuarios de estas. Lo que confiere a las cosas carácter de mercancía es nuestra relación alienada con ellas (más adelante veremos en qué consiste esta relación). No es de extrañar, en consecuencia, que Marx se refiriera al fetichismo de la mercancía y a la naturaleza suprasensible de sus propiedades.

Marx utiliza el concepto de forma en el sentido originario de la filosofía griega, es decir, como algo eidético, pero al mismo tiempo, en relación al valor, lo dota de un contenido psicológico y psicosociológico para denotar su pertenencia al mundo de lo suprasensible, de lo fantasmagórico, de lo patológico: el valor es algo que aparece, que toma forma ante nuestros ojos sin que seamos conscientes de ello; esta forma puede ser corpórea o no (la transmisión de conocimiento, por ejemplo), pero no deja de ser una proyección de nosotros mismos y de nuestras relaciones en un objeto, sea este material o espiritual. Necesitamos la psicología social porque estamos tratando con un espejismo intersubjetivo sobre el que se sostiene el funcionamiento de la sociedad. De este hecho se puede inferir lógicamente una conclusión a la que también se ha llegado por otros caminos: la sociedad está enferma.

Así, a la mercancía no hay que imaginarla como un objeto físico (aunque tendamos irremisiblemente a ello) sino, simplemente, como un elemento cualquiera portador de valor, del mismo modo como el aire porta el sonido (con la salvedad de que este es un hecho físico, mientras que el otro es de otra naturaleza, cercana al objeto de estudio de los alienistas). Para que exista la mercancía deben coincidir dos cosas: el valor y un elemento que lo transporte (más adelante veremos que, en rigor, no es así, puesto que el valor puede existir independientemente de las cosas portadoras de valor: en forma numérica ${ }^{9}$ ).

${ }^{9}$ Uno de los efectos de esta escisión son las crisis financieras modernas. 
El primer apartado del capítulo primero de El Capital se titula "Los dos factores de la mercancía ${ }^{10}$ : valor de uso y valor (substancia de valor, magnitud de valor)". Aquí nos presenta Marx la mercancía como algo que tiene dos aspectos diferentes aunque necesariamente complementarios: la mercancía posee, por un lado, propiedades (sean físicas o no) que la distinguen de las otras mercancías (esto no es un hecho banal), y que le confieren su utilidad o valor de uso (no importa de qué tipo de uso se trate); pero también tiene otra cualidad que comparte con las otras mercancías: la capacidad de representar valor, análogamente a como un embajador representa un país (enseguida veremos en qué consiste este valor "a secas").

La mercancía no es el objeto simple e inocente que "percibimos", sino que presenta una estructura ${ }^{11}$ harto compleja. Como cosa útil y concreta, que satisface necesidades o deseos (el substrato de la mercancía), tiene propiedades que causan ciertos efectos en su usuario, que pueden ser físicos (por ejemplo, los nutrientes de un bocadillo o los estímulos en el nervio óptico causados por las emisiones de fotones que rebotan en la pantalla sobre la cual se proyecta una película) o psíquicos (como el placer de comer el mencionado bocadillo o de ver una buena película, o ambas cosas a la vez).

Sin embargo, como depositaria de cierto valor abstracto ${ }^{12}$ latente la mercancía tiene propiedades psicológicas (este valor es, en última instancia, ficticio - ya se verá por qué- aunque "para nosotros" se manifieste en el mundo real de modo más o menos contundente). Y, por último, la mercancía, como cosa capaz de interactuar con otras cosas análogas, actualizando en esa relación el mencionado abstracto valor latente, tiene, además, propiedades psicosociales, esto se puede evidenciar en la Figura 1, presente a continuación.

Este esquema muestra la mercancía como un conjunto de círculos concéntricos. El núcleo (V.U. o valor de uso) es la cosa en sí, sin añadidos, una cosa concreta que puede satisfacer cualquier tipo de necesidades o deseos. El siguiente círculo (V. o valor) pertenece al ámbito psicológico: la cosa, cuya utilidad es inexistente, es, no obstante, el vehículo de un valor latente, por el mero hecho de haber invertido tiempo (y, quizás, esfuerzo) en su producción. El círculo siguiente (V.C. o valor de cambio) se refiere al espacio psicosocial donde tiene lugar la relación entre mercancías, la cual "despierta" el valor latente y lo inviste de valor de cambio reflejándolo en el valor de uso de otra mercancía (el único tipo de valor tangible "para nosotros").

\footnotetext{
${ }^{10}$ La mercancía es simplemente un soporte del valor; una mercancía es, pues, una cosa portadora de valor (puede ser tangible, como un lápiz o una piedra de color, o intangible, como la fuerza de trabajo o una voluntad; puede ser material o "espiritual").

${ }^{11}$ Ver pie de página 2.

${ }^{12}$ Es abstracto porque es independiente del objeto que lo porta y tan solo podemos estudiarlo haciendo abstracción del mismo; y es latente porque solo se manifiesta, como veremos más adelante, en una situación específica.
} 
Figura 1. Estructura de la mercancía

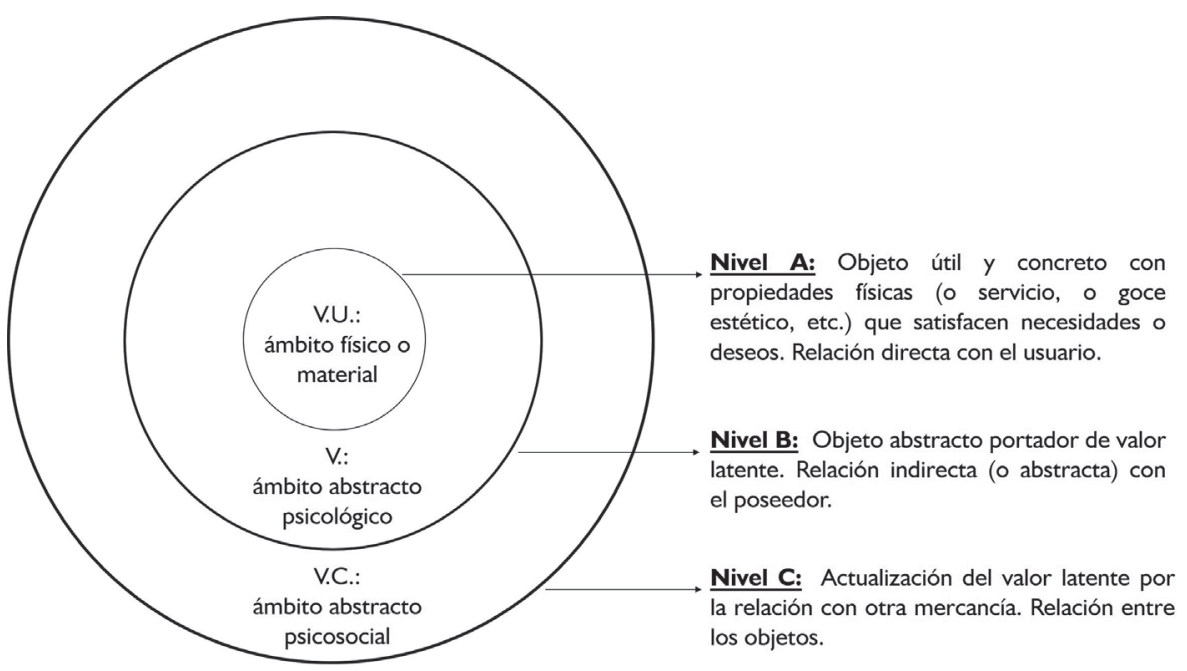

Fuente: Ideograma diseñado por el autor para visualizar el concepto desarrollado por Marx en Das Kapital

En el segundo apartado, intitulado "Dúplice carácter del trabajo representado en las mercancías", comprobamos que, los diferentes elementos integrantes de la mercancía vistos anteriormente, tienen su correlato en dos aspectos distintos del trabajo productor de la mercancía: del mismo trabajo se obtiene, por una parte, utilidad (una cosa útil sea cual sea su "utilidad"); por el otro lado, se obtiene valor (es decir, algo, al menos aparentemente, inútil); por un lado, obtenemos algo concreto, y por el otro, algo abstracto.

En consecuencia, el trabajo productor de mercancías es un trabajo ambivalente: es simultáneamente una actividad concreta y abstracta, constituyendo este (en sentido clínico) morboso proceso uno de los "condimentos" de la alienación ${ }^{13}$ (ver Figura 2). Sobre lo que nos ocupa, dice Marx: "Como este es el punto crítico en torno al cual gira la comprensión de la economía política, vale la pena iluminarlo aquí más detalladamente" (1976, p. 49). En otras palabras, para Marx, es absolutamente necesaria la comprensión dialéctica ${ }^{14}$ del trabajo ${ }^{15}$, es decir,

\footnotetext{
${ }^{13}$ Para una mejor comprensión de mi enfoque de este concepto léase mi tesis doctoral: El concepte d'alienació al pensament de Karl Marx (Soler i Alomà, Jordi; Universitat de Barcelona, 2002) o léase mi ponencia en el Congreso Internacional de Filosofía (Habana, 2004) Sociedad y Alienación: Vigencia de los Planteamientos de Marx en el Análisis Del Mundo Actual.

${ }^{14} \mathrm{O}$ sea, la asimilación de un concepto que se resiste al análisis convencional por la vía de la argumentación y de la síntesis de lo diacrónico y lo sincrónico.

${ }^{15}$ Hay que evitar la confusión entre trabajo y fuerza de trabajo, que son dos conceptos diferentes bien definidos y delimitados por Marx en Das Kapital. El trabajo es la actividad productiva alienada en el marco de la sociedad capitalista mientras que la fuerza de trabajo es la mercancía humana objeto de compraventa.
} 
de la paradójica dúplice naturaleza concreta y abstracta que hemos descrito anteriormente. De este asunto deberemos tratar, más adelante, con mayor detalle.

Figura 2. Doble carácter del trabajo

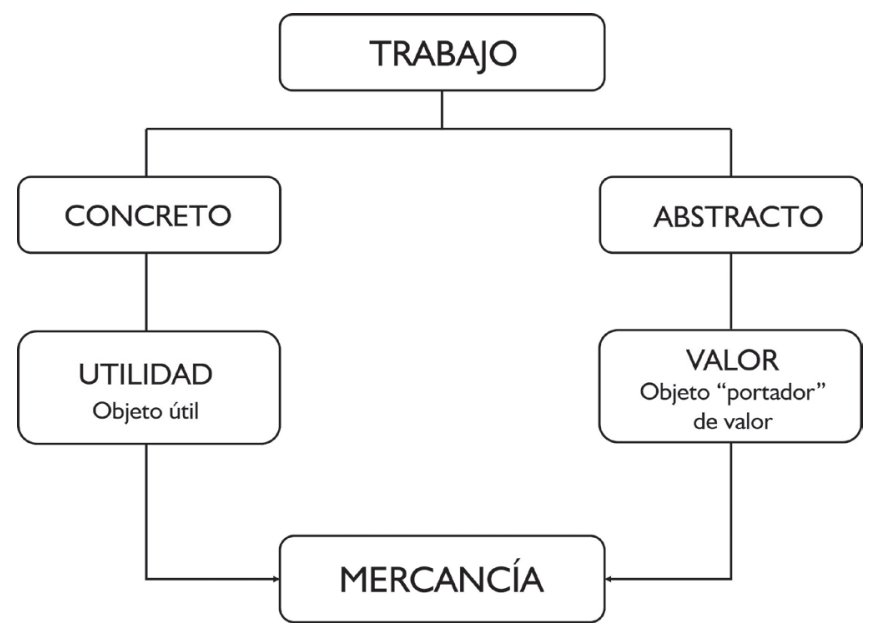

Fuente: Ideograma diseñado por el autor para visualizar el concepto desarrollado por Marx en Das Kapital

En el sistema capitalista la producción alienada se conoce como trabajo y se despliega en dos espacios: a) el espacio de lo concreto y lo útil (en el sentido de poder ser usado no importa para qué) y b) el espacio de lo abstracto y del tiempo cosechado. La yuxtaposición de ambos espacios da como resultado la mercancía.

Pero pasemos ahora a afrontar ilo más crucial de El Capital!, que es el contenido del tercer apartado del primer capítulo, cuyo título reza "La forma de valor, o valor de cambio". El tema que tratamos ahora es "A) La forma de valor simple singular o casual"16. En este lugar es imprescindible atenerse a lo que contundentemente sentencia Marx —algo sobre lo que anteriormente ya se ha hecho asaz hincapié- en cuanto a dicha forma de valor: "El misterio de toda forma de valor está contenido en esta forma de valor simple"; ¿qué quiere decir Marx con las palabras "el misterio"? dicho término es el referente de lo que ya se ha expuesto reiteradamente: que la forma mercancía y, especialmente, la forma dinero, no son simples objetos ni simples relaciones de cambio, sino que pertenecen a un escabroso territorio psicosocialmente muy intrincado, en el cual las cosas, como veremos, poseen propiedades sobrenaturales (es decir, poseen las mismas propiedades que definen a algunas colectividades de seres vivientes y, concretamente, a la especie humana: poseen características sociales, aunque

\footnotetext{
${ }^{16}$ Marx llama simple a esta forma de valor en un sentido literal: es la menos compleja, y la llama casual porque solo se realiza en intercambios ocasionales, o sea, que es simple y casual.
} 
de modo alienado). Y, en consecuencia, debe tomarse en serio la advertencia de Marx que sigue a la frase que se ha mencionado: "Por eso es su análisis el que presenta la verdadera dificultad". Hay que leer este párrafo de Marx tantas veces como sea necesario para tomar conciencia de la importancia del asunto.

En efecto, la tarea más difícil que puede afrontar un cerebro humano es investigar en el ámbito de lo que de antemano rige la realidad en la que "existimos", aquello que siempre está ya dado por supuesto; aquello que constituye (no en el sentido kantiano, sino en el hegeliano) a priori la realidad... en fin, lo que nunca se cuestiona porque es, a pesar de todo, el suelo que nos sostiene (para aducir una analogía que plasme lo complejo del ejercicio que Marx nos propone, sería algo así como ver, a través de nuestros ojos, nuestros propios ojos).

Nosotros "vemos" un objeto (físico o no) como mercancía, porque previamente hemos interiorizado esta forma para poder proyectarla sobre el objeto y percibirla como propia del mismo (de manera similar a como funciona el proceso de la percepción en Kant). Si no conocemos las reglas del juego que siempre estamos ya jugando es porque rige una norma subyacente, de naturaleza consuetudinaria (si es que no la hemos incorporado ya en el ADN), según la cual no se debe indagar acerca de las reglas ocultas. Esta norma subyacente funciona automáticamente y no tenemos conciencia de su existencia; actúa como una puerta que se cierra cuando se roza el umbral de peligro. Es uno de los mecanismos de bloqueo que dificulta la lectura cabal del capítulo "maldito" de El Capital.

Podemos afirmar, en consecuencia, que ante la "realidad" que se nos impone a los seres humanos que padecemos el proceso histórico regido por el mecanismo llamado "sistema capitalista" realizamos un perpetuo acto de fe psicosocial, análogo al que requieren a sus fieles las religiones; a saber: que lo que llamamos la "realidad" es consistente (cuando ya tenemos pruebas de que dicha afirmación es, por lo menos, cuestionable). Lo que diferencia el capitalismo de todos los sistemas de organización social, que a lo largo de la historia se han basado en la explotación del hombre por el hombre, es que el sistema capitalista es el más sofisticado en la tecnología de la sugestión masiva, porque esclaviza tanto los cuerpos como las mentes, ya que es la única sociedad en la que los esclavos creen ser libres. En otras sociedades los esclavos son conscientes de su situación, y pueden tratar de modificarla (por ejemplo, la lucha de los esclavos liderados por Espartaco, que terminó, lamentablemente, con la masacre de los mismos, o la lucha de los esclavos haitianos de 1791 a 1804, los cuales derrotaron a las tropas de las mayores potencias coloniales y llegaron a proclamar la independencia).

En la sociedad capitalista, las personas portamos el anuncio de "se vende" sin que nos demos cuenta de ello. Unicamente en los momentos más álgidos de la lucha de clases, la clase proletaria ha tenido autoconsciencia. Por el contrario, los miembros de las oligarquías (en el sentido lato del concepto) son perfectamente 
conscientes de la clase a la que pertenecen; prueba de ello es que un representante de dicha clase, Warren E. Buffett, dijo en una entrevista a la agencia Reuters publicada por el New York Times (en un artículo de Ben Stein) el 26 de septiembre de 2006: "There's class warfare, all right, but it's my class, the rich class, that's making war, and we're winning". La oligarquía reconoce que hay lucha de clases, que es ella quien lleva la iniciativa y, además, que va ganando. A partir de este momento, deberemos tener siempre presentes dos preceptos:

1. Como ya se ha visto, Marx emplea el concepto forma en un sentido rayano al del concepto etimológico griego ${ }^{17}$, es decir, como connotativo de las determinaciones intersubjetivas ${ }^{18}$ que, a través de un proceso consuetudinario, solidifican idiosincrásicamente, constituyendo los elementos a priori de la praxis: de antemano, confieren un sentido concreto a lo que captamos encajándolo en un marco de referencia: la ideología ${ }^{19}$.

2. Marx, para hacer más palpable la dialéctica de la mercancía, le cede todo el protagonismo, al mismo tiempo que le otorga una cierta "subjetividad" que facilita una cierta proximidad con aquella $y$, de esta guisa, la asimilación dialéctica de su proceso.

Para desarrollar su argumentación Marx aduce dos "productos" relacionados entre sí: el lino ${ }^{20}$ y la levita ${ }^{21}$. Observemos que el lino es uno de los medios de producción de la levita, de modo que, hábilmente, Marx nos ofrece ejemplos de dos tipos de mercancía que cumplen una función distinta en este complejo engranaje: el lino, como ejemplar de mercancía del tipo "medio de producción" y la levita, como ejemplar de mercancía del tipo "normal" que se puede ver en cualquier escaparate. Como ya habrá notado el lector, la levita no es un tipo de mercancía de uso muy común; entonces ipor qué la usa Marx como ejemplo?

\footnotetext{
${ }^{17}$ Marx emplea el concepto de forma en múltiples ocasiones; por ejemplo, lo usa para referirse a la forma de valor, a la forma de mercancía del producto del trabajo, a la forma dinero de la mercancía ¿qué quiere decir? Está usando forma en el sentido filosófico. En este contexto, el concepto de forma se remonta a los orígenes de la filosofía ática (eidos); tenía un significado próximo al de nuestra "idea", pero en el sentido no de algo construido a partir de lo percibido, sino de algo que regula la percepción. Nosotros proyectamos formas sobre la realidad, que configuramos en función de dichas formas. Son formas que no son inherentes a las cosas, sino que somos nosotros los que las proyectamos sobre ellas, proyecciones que proceden de nuestras relaciones interpersonales alienadas en los objetos; es a eso a lo que Marx se refiere cuando habla de las propiedades sociales de las cosas.

${ }^{18}$ Intersubjetivo: relativamente objetivo.

${ }^{19}$ Ideología: conjunto de criterios con los que una sociedad interpreta y juzga la realidad y se relaciona con ella; en todos los sistemas sociales históricos rige la ideología de la clase dominante.

${ }^{20} \mathrm{El}$ lino es una planta herbácea, anual, de la familia de las lináceas, con raíz fibrosa, tallo recto y hueco, como de un metro de alto y ramoso en su extremidad, hojas lanceoladas, flores de cinco pétalos azules, y fruto en caja de diez celdillas, con una semilla aplanada y brillante en cada una. De su tallo se extraen fibras que se utilizan para producir la hilaza, con la que se elabora la tela de lino.

${ }^{21}$ Vestidura masculina de etiqueta, más larga y amplia que el frac, y cuyos faldones llegan a cruzarse por delante.
} 
La razón es simple: Marx quiere evitar la contaminación del análisis que podría causar la perniciosa familiaridad con un tipo de mercancía como podría ser, por ejemplo, el pan. El objetivo de Marx es que haya una saludable distancia entre el lector y la mercancía-ejemplo, para favorecer el proceso de abstracción. Si Marx hubiera aducido ejemplos como la harina y el pan, se hubiera expuesto a que las connotaciones excesivamente familiares de ambos objetos interfirieran en este delicado proceso.

Dando por asumida la nota pedagógica de Marx, procederemos a acompañarlo en su análisis, poniéndonos en el pellejo de una familia campesina: supongamos que fabricamos lino para vestir a nuestra familia y que hemos producido intencionadamente cierta cantidad de lino excedente, con el objeto de cambiarla por una levita, supuestamente debido a que su futuro usuario precisa del atuendo adecuado para asistir a reuniones sociales en las que se requiere cierto decoro y especificidad en la vestimenta. Si calculamos (luego veremos cómo se lleva a cabo el proceso) el valor de la cantidad concreta de lino y el de una unidad de levita, podemos concluir, del mismo modo que hará el sastre, que $20 \operatorname{codos}^{22}$ de lino valen 1 levita, estableciendo la siguiente igualdad: 20 codos de lino $=1$ levita .

Esto significa, ni más ni menos, que el valor de cambio de veinte codos de lino es una levita. Sin embargo, algo que parece natural no lo es en absoluto: ¿cuál es el origen de ese valor de cambio? no hace falta ser un erudito para saber que no es lo mismo la tela de lino que la levita; por consiguiente, en la igualdad 20 codos de lino $=1$ levita se halla oculto algo que debe ser común a ambas cosas pero que no guarda ninguna relación con su utilidad ni con sus propiedades físicas. Dicho de otro modo, esta igualdad iguala algo que no es observable por medios convencionales (por más sofisticados que sean). La única propiedad común que tienen el lino y la levita, después de haber hecho abstracción de todas las propiedades observables o mensurables, no es una propiedad visible ni tangible, pero que, no obstante, es la única propiedad común a todas las mercancías: esta propiedad común es la de ser productos de la actividad humana.

Volviendo a nuestra familia campesina: la tela de lino que hemos producido para cubrir las necesidades de vestimenta de los miembros de nuestra familia tiene, para nosotros, un valor de uso, una utilidad, que se satisface simplemente con su uso (que no solo es práctico, sino que también puede ser estético); en cambio, la tela de lino que hemos producido para cambiarla por cosas útiles para nuestra familia, no tiene, para nosotros, valor de uso (carece de utilidad alguna); a pesar de eso aunque este sea imperceptible, contiene otro tipo de valor: un valor que establecemos en función del esfuerzo (por utilizar una expresión descriptiva) que nos ha costado producir la cantidad de tela excedente; este esfuerzo tiene carácter objetivo y subjetivo (físico y psíquico) y necesitamos un modo de medirlo;

${ }^{22}$ Medida lineal, que se tomó de la distancia que media desde el codo a la extremidad de la mano. 
como sea que el proceso de producción (como todo proceso) tiene lugar en el tiempo ${ }^{23}$, decidimos establecer la medida de su valor en las unidades de tiempo de que ya disponemos desde que el mismo se mide ${ }^{24}$.

Se define el valor de una cosa, por tanto, mediante la cantidad de tiempo que se suele emplear en producir tal cosa. Parece simple, pero el tiempo no es algo que se pueda empaquetar; por más que lo intentemos, tempus fugit. Lo único que podemos hacer es forjar la ilusión colectiva de que el tiempo está "empaquetado" en nuestros productos. A este empaquetamiento virtual (gelatina de trabajo, según Marx) le ponemos un número (que tan solo expresa una cantidad de algo abstracto), y mediante este "ingenioso" procedimiento icreemos que realmente hemos logrado capturar el tiempo en forma de valor!, una cosa invisible, intangible para los mortales comunes, y aun misteriosa para los físicos como es el tiempo iempaquetado en una humilde y vulgar mercancía!

Como ya puso de manifiesto Hegel en su Lógica (verba ex memoria), ni una operación matemática como la suma puede ocultar el hecho de que se igualan cosas diferentes. Por ejemplo, $1+1=2$ nos aparece como algo simple y evidente; sin embargo, podemos observar que en el lado izquierdo hay una cantidad mayor de signos que en el lado derecho, y, por cierto, en dicho lado también se ha usado más cantidad de tinta; visualmente (o gráficamente), el lado izquierdo no es igual que el lado derecho, etc. Además ¿cuál es exactamente el rol que desempeña el signo "="? No parece que sea manifiestamente ostensible: ¿qué significa "igual a"?, ¿qué es "lo" idéntico?, ¿qué es "lo" intercambiable? Ninguna de estas preguntas tiene una respuesta "cómoda". Las dos expresiones numéricas, "1+1" y "2", solo son igualables en función de una "cosa": la cantidad pura (algo que, como se sabe, no existe); ambos términos connotan, por ende, la misma cantidad de nada en concreto. Pues bien, la expresión 20 codos de lino = 1 levita iguala ambos términos en función de ese otro "algo": el valor (otra cosa que itampoco existe!); en ambas cantidades de cosa diferente que hay a ambos lados de la igualdad hay el mismo contenido (imaginario) de valor. Por consiguiente, "20 codos de lino = 1 levita" suponen que la cantidad de lino producido ha empleado el mismo monto de tiempo (de ahí el valor — tiempo "congelado" y "empaquetado") que para confeccionar la levita. Tras ese fenómeno, que a primera vista aparece como trivial y hasta inocente, se esconde lo que podríamos Ilamar la "Caja de Pandora" de la Historia (sobre la cual ya dijo el gran Aristóteles que mejor cerrarla cuando aún se estaba a tiempo — verba ex memoria).

\footnotetext{
${ }^{23}$ Sería más correcto decir que tiene lugar en el espacio-tiempo; pero, del mismo modo que hace la economía, haremos aquí también abstracción del espacio (que a fin de cuentas se puede separar del tiempo).

${ }^{24}$ Dejaremos a un lado la discusión sobre el carácter arbitrario de este "fraccionamiento" de algo que es continuo, aunque todo encaja en el país de las maravillas del capital.
} 
Prosiguiendo con el análisis dialéctico de la mercancía, Marx nos lleva al punto de no retorno ${ }^{25}$ : "Los dos polos de la expresión de valor: forma relativa y forma equivalente de valor". La mercancía cuyo valor es "expresado" lo hace representándolo (o, permítaseme la licencia: representándoselo) como valor relativo. La mercancía con la cual se pone de manifiesto (o se expresa) el valor de la otra lo hace representando el papel de equivalente. En el sistema de categorías de Marx, la primera mercancía reviste la forma relativa mientras que la segunda mercancía reviste la forma equivalente.

Para comprender cómo la mercancía llega a su pleno desarrollo cuando asume la forma dinero, hay que entender de forma cabal en qué consisten las dos formas que asumen previamente. Los economistas, en su inmensa mayoría, cuando no se toman en serio este problema; obviamente porque no lo entienden y, si lo entendieran, no lo aceptarían, porque se verían compelidos no solo a reconsiderar su actitud "científica", sino, también, a cuestionar su moral. Para la economía ortodoxa (economía liberal, macroeconomía, etc.) Marx es un heterodoxo y un hereje, del mismo modo que lo fue Copérnico para la ortodoxia geocéntrica.

\section{El secreto de la forma relativa}

La forma relativa de valor reviste un carácter misterioso, para cuya investigación debemos adentrarnos en el mundo de los "espíritus", ya que, mutatis mutandis es el lugar donde reside. Supongamos que el lino está poseído por un espíritu, y que este espíritu solo se puede ver a través de un espejo especial, parecido a los que se usan en las películas sobre fantasmas, y que es capaz de devolver la imagen del espíritu que lo posee: es decir, cuando el lino se pone frente a este espejo, lo que se ve no es la tela de lino, sino la imagen de una levita. Esta analogía ilustra lo que sucede en la realidad: en el proceso intersubjetivo en que tiene lugar la forma relativa de valor, "vemos" el valor —o componente "espiritual" — de una mercancía reflejado por el cuerpo —o substrato físico- de otra mercancía (existen condiciones más enmarañadas de reflejo del valor, pero es mejor ilustrar el análisis de modo razonablemente inteligible).

Ha llegado el momento de ver cómo Marx nos desvela el contenido de la forma relativa de valor. Para ello, Marx afirma algo paradójico: "Para averiguar cómo está inserta en la relación de valor entre dos mercancías la expresión simple de valor de una mercancía hay que considerar por de pronto esa relación con completa independencia de su aspecto cuantitativo" (1976, p. 57). Nota bene: lo que igualamos no son simples cantidades, sino que son cosas distintas.

${ }^{25}$ Si hemos llegado hasta aquí, ya no tiene sentido volver atrás. 
El factor cuantitativo solo nos interesa por algo que es ajeno a la propia naturaleza de lo que connotan los miembros de la igualdad. Por ende, lo que cabe destacar aquí es el hecho en sí de que se igualen cosas de distinta naturaleza. En cambio, no nos interesan las cantidades en que son igualables, cuyo carácter es contingente ¿cómo ha sido si no abstrayendo de la cantidad que nos hemos dado cuenta de ello? La arquitectura alienada de nuestra mente nos impedía ver que tras la relación de valor que siempre habíamos asumido como una comparación cuantitativa se escondía una relación de igualdad entre objetos diferentes, los cuales únicamente pueden ser igualables si son reducidos a aquello que es común a ambos: lo que tienen socialmente en común.

Haciendo abstracción, por ende, de lo cuantitativo, podemos reducir legalmente la anterior igualdad a la siguiente: Lino = levita. La constatación, que puede parecer hegeliana, de que tan distintos objetos solo son igualables por sus propiedades metafísicamente sociales es lógicamente necesaria. En palabras de Marx:

Cuando decimos que las mercancías no son, en cuanto valores, más que gelatina de trabajo humano, nuestro análisis las reduce, pues, a la abstracción valor; pero no por eso les da ninguna forma de valor distinta de sus formas naturales. La situación cambia cuando se trata de la relación de valor entre una mercancía y otra (1976, p. 58).

Por consiguiente, la tela de lino que nos ha sobrado, en sí misma, es decir, como tiempo de trabajo solidificado presume cierto valor en potencia. El análisis dialéctico de la mercancía ha puesto en evidencia que lleva una "doble vida"; es un objeto que existe en dos "universos paralelos": por un lado, la mercancía existe como un objeto útil, concreto (no puede no serlo), investido de un conjunto de propiedades (físicas o empíricas), y por otro lado existe como un ente metafísico y abstracto, portador de propiedades "sociales" y "psicosociales". En este segundo "modo de existencia", la mercancía se puede reducir a valor a secas, debemos recordar aquí, siguiendo el método científico de Marx, que estamos haciendo abstracción de toda determinación cuantitativa; de hecho, en la constatación de que un objeto cualquiera tiene el carácter de mercancía va implícito el reconocimiento de su valor. Al ver la tela de lino ya "percibimos" su valor (cualitativamente). Sin embargo, no basta con "percibir" o "tener la sensación" de que la tela de lino contiene valor; para determinarlo, la tela de lino se remite a la levita (como cualquier mercancía debe remitirse a otra); en ese proceso el valor de la tela de lino reviste la forma de levita, de tal modo que, en esa relación, se actualizan propiedades que fuera de ella tan solo existían en potencia.

Como ya hemos observado, la cantidad de tela de lino que nos ha sobrado, para nosotros, no tiene ninguna utilidad, sin embargo, ahora sabemos que su valor latente reside en el hecho de que nos ha costado un esfuerzo producirla y que ese esfuerzo, congelado y empaquetado en la forma mercancía, puede 
transcender cuantitativamente en el proceso de cambio. Si esa "transcendencia" no fuera posible, el lino sobrante iría directamente al basurero o al contenedor de reciclaje, ya que para nosotros carecería de valor alguno.

Al comparar la tela de lino con la levita, lo que estamos haciendo es expresar el valor del lino por medio (médium) de la levita, la cual, gustosamente, interpreta el papel de equivalente de la tela de lino. Como todos saben a nuestro vecino sastre también le ha requerido cierto esfuerzo (y determinada cantidad de unidades de tiempo) la confección de la levita, entonces, ¿qué ha sucedido en todo ese proceso? Sencillamente: hemos comparado (respecto a la producción de tela de lino y a la confección de una levita) los "esfuerzos" respectivos; es decir, nosotros, como tejedores, y el vecino, como sastre. Hemos considerado nuestros respectivos trabajos concretos como trabajo en general, o sea, trabajo abstracto ${ }^{26}$, y en ese proceso de abstracción lo hemos reducido a un solo factor: el tiempo. En palabras de Marx:

Así, pues, en la relación de valor en la que la levita constituye el equivalente del lino la forma-levita funciona como forma-valor, como forma de valor, por lo tanto, el valor de la mercancía lino se expresa en el cuerpo de la mercancía levita: el valor de una mercancía en el valor de uso de otra (1976, p. 59).

La última frase del párrafo es reveladora: el valor de la tela de lino se expresa ¿en qué?, en el valor de uso de la levita. Si seguimos desarrollando la igualdad propuesta por Marx (lino=levita) obtendremos: Valor=Valor de uso. ¿Cómo se resuelve esa paradoja? La solución se halla en nuestra cabeza, en cuanto productores de tela de lino. Cuando optamos por cambiar nuestro lino por la levita lo hacemos teniendo en la mente que la levita, al menos para nosotros, tiene una utilidad; en otras palabras, cuando estamos cambiando la tela de lino por la levita, la levita está interpretando para nosotros el papel de valor de uso, si no fuera así ipor qué motivo iríamos a cambiar la levita por nuestra tela de lino? Ponemos de manifiesto, por tanto, el valor de nuestra tela de lino en algo que nos es útil. Como se ha dicho antes: representamos el valor de una mercancía en el valor de uso de otra mercancía. Prosigamos con el análisis de Marx:

Como se ve, el lino mismo nos dice, en cuanto que entra en trato con la otra mercancía, con la levita, todo lo que antes nos había dicho el análisis del valor de las mercancías. Solo que traiciona sus pensamientos en el único lenguaje que le es corriente, en el lenguaje de las mercancías. Para decir que el trabajo, en su propiedad abstracta de trabajo humano, constituye su propio valor, el lino dice que la levita consta del mismo trabajo que él mismo en la medida en que le es equivalente, o sea, en la medida en que es

\footnotetext{
${ }^{26}$ Abstraer: Separar por medio de una operación intelectual las cualidades de un objeto para considerarlas aisladamente o para considerar el mismo objeto en su pura esencia o noción. En este caso, hemos hecho abstracción de todas las propiedades menos de una: la duración.
} 
valor. Para decir que su sublime objetividad de valor es cosa diferente de su rígido cuerpo de lino, dice que el valor tiene el aspecto de una levita, y que por eso él mismo, el lino, se parece, en cuanto cosa-valor, a la levita como un huevo a otro (1976, p. 60).

El lino, que habríamos podido tirar a la basura, porque el valor latente, testimonial y abstracto no sirve para nada y, por añadidura, ocupa espacio, el lino (decía) cobra importancia por el hecho de que la levita descubre que él también vale. Este lino, pues, traiciona sus pensamientos y se delata a sí mismo: el valor, que se le suponía propiedad intrínseca suya, resulta que es un añadido externo, y eso se pone de manifiesto en su relación con la levita. En palabras de Marx:

Así, pues, mediante la relación de valor la forma natural de la mercancía B se convierte en la forma de valor de la mercancía A, o sea, el cuerpo de la mercancía $B$ se convierte en espejo del valor de la mercancía $A^{27}$. La mercancía $\mathrm{A}$, al referirse a la mercancía $\mathrm{B}$ como a cuerpo de valor, como a materialización de trabajo humano, convierte el valor de uso B en material de su propia expresión de valor. El valor de la mercancía A, así expreso en el valor de uso de la mercancía B, tiene la forma del valor relativo (1976, p. 61).

Una vez explorado el aspecto cualitativo de la forma relativa de valor (véase figura 3), que es el único modo de captar la esencia que se esconde detrás de la apariencia, deberemos afrontar, también, la tarea de explorar su lado cuantitativo, puesto que es su modo de manifestación natural. Esto nos conduce al apartado: "b) Determinación cuantitativa de la forma de valor relativa", en el cual Marx desarrolla este argumento:

La igualdad $« 20$ codos de lino $=1$ levita, o bien 20 codos de lino valen 1 levita» presupone que haya en 1 levita exactamente tanta substancia de valor como en 20 codos de lino, o sea, que ambas cantidades de mercancía cuesten la misma cantidad de trabajo, el mismo tiempo de trabajo. Pero el tiempo de trabajo necesario para la producción de 20 codos de lino o de 1 levita cambia cada vez que cambia la fuerza productiva del tejer o de la sastrería (1976, pp. 61-62).

Observemos, de paso, que el valor de una mercancía dependerá (entre otros factores) del procedimiento empleado para su producción:

\footnotetext{
${ }^{27}$ En cierto modo pasa con el hombre como con la mercancía. Puesto que no llega al mundo con ningún espejo, ni tampoco en condición de filósofo fichteano, con su «Yo soy yo», el hombre empieza por reflejarse en otro ser humano. El hombre Peter no se relaciona consigo mismo en cuanto ser humano sino a través de la relación con el hombre Paul. Mas con eso mismo resulta que Paul es para él, con todos sus detalles, con toda su paulina corporeidad, la forma de manifestación del género humano (Nota de Marx).
} 
[...] resulta que un mismo cambio de magnitud del valor relativo puede nacer de causas totalmente contrapuestas. Así, partiendo de 20 codos de lino $=1$ levita se tiene, $1^{\circ}$, la igualdad 20 codos de lino $=$ dos levitas ya porque se duplique el valor del lino, ya porque el valor de las levitas disminuya hasta la mitad, y $2^{\circ}$, la igualdad 20 codos de lino $=1 / 2$ levita ya porque el valor del lino disminuya en una mitad, ya porque el valor de la levita aumente hasta el doble (1976, p. 62).

Figura 3. Forma relativa de valor

\section{FORMA RELATIVA DE VALOR}

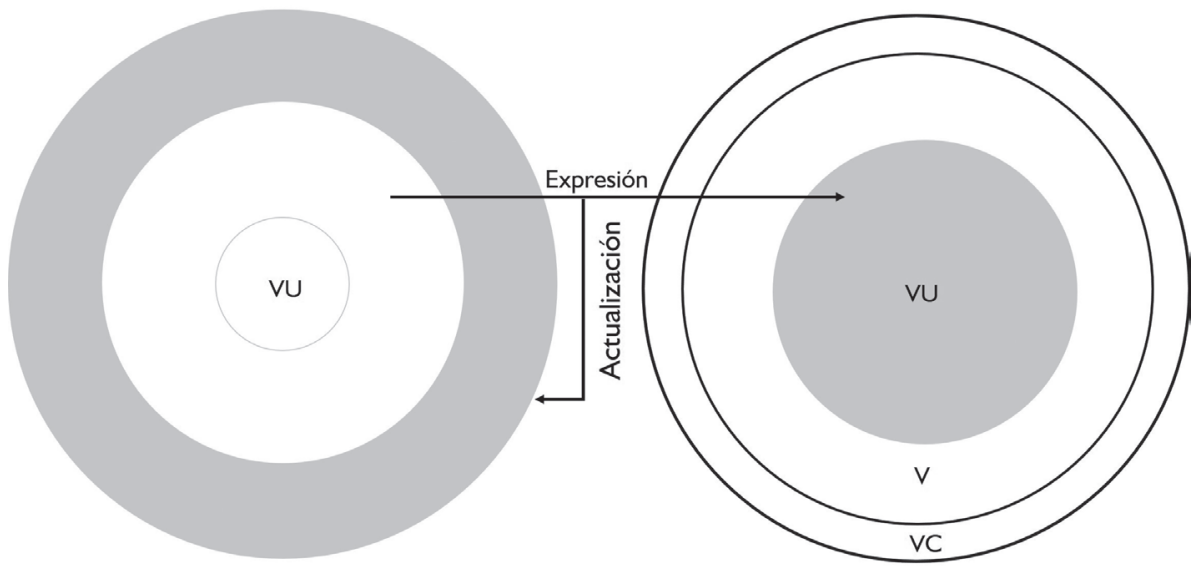

El valor latente $\mathrm{V}$ de la mercancía $\mathrm{A}$ se actualiza como valor de cambio al reflejarse en el valor de uso $V$ de la mercancía $B$. Se puede observar el menor tamaño de VU en la mercancía B, a diferencia del mayor tamaño en $\mathrm{A}$. Esto es para poner de manifiesto que de la primera, solo interviene aquí el valor y el valor de cambio, mientras que de la segunda solo interviene el valor de uso. Estamos prescindiendo, con Marx, de los aspectos cuantitativos.

\section{MERCANCÍA B}

Fuente: Ideograma diseñado por el autor para visualizar el concepto desarrollado por Marx en Das Kapital

Todo se debe a las variaciones coyunturales que afecten a la producción de una u otra mercancía. En palabras de Marx:

[...] los cambios reales de la magnitud de valor no se reflejan ni inequívoca ni completamente en su expresión relativa, en la magnitud del valor relativo. El valor relativo de una mercancía puede cambiar aunque permanezca constante su valor. Su valor relativo puede permanecer constante, aunque su valor cambie, y, por último, no es forzoso que coincidan los cambios simultáneos de su magnitud de valor con los de la expresión relativa de esa magnitud (1976, p. 63). 
Observemos que ejemplos palpables de esas variaciones del valor los padecemos en fenómenos como la inflación, la devaluación, etc. Los especuladores financieros obtienen pingües beneficios con las fluctuaciones bruscas de valor, que siempre son a su favor (porque si la cosa sale mal, las pérdidas son "socializadas"), y en perjuicio de terceros (que suelen ser los pequeños accionistas y el resto de la sociedad).

Aunque nos resulte paradójico, para determinar el valor hay que reducir la activad humana concreta, determinada cualitativamente, a algo indeterminado, puramente cuantitativo, cuando la evidencia nos dice que si por algo la actividad humana es humana es por su especificidad cualitativa, y es, además, siendo cualitativamente específica como crea riqueza. Pero, si como intermediarios que somos entre las mercancías, debemos hacer del tiempo objeto de compraventa no hay otro modo de "empaquetarlo" que el que se ha analizado.

\section{El secreto de la forma equivalente}

La tela de lino, como Alicia, ya ha visto lo que hay en el espejo. Ahora, ha llegado el momento de pasar a través de él. Ha llegado el momento de ver en qué consiste "La forma de equivalente" (véase la Figura 4) y, para introducirnos en este ignoto territorio, nadie mejor que su descubridor, Marx, como pathfinder:

Como se ha visto, cuando una mercancía A (el lino) expresa su valor en el valor de uso de una mercancía de otra especie, B (la levita), imprime a esta última una peculiar forma de valor, la forma de equivalente. La mercancía lino, pone de manifiesto su valer a través del hecho de que la levita, sin tener que suponer una forma de valor diferente de su forma corpórea, vale lo mismo que ella. Así, pues, el lino expresa de hecho su propio valer por la circunstancia y en la circunstancia de que la levita es inmediatamente intercambiable con él. Consiguientemente, la forma de equivalente de una mercancía es la forma de su intercambiabilidad inmediata con otra mercancía (1976, p. 64).

En otras palabras, lo que hay al otro lado del espejo es la relación de la tela de lino con la levita que consiste en la intercambiabilidad "de suyo". Es decir, lo que hay al otro lado del espejo es la forma equivalente vestida de levita. Sin embargo, la mercancía que hace de equivalente en esa relación no puede expresar su valor, sino únicamente sirve para expresar el valor de que se refiere a ella como a equivalente; si frente al "espejo-levita" ponemos una levita ninguna imagen de valor se verá reflejada, ya que una mercancía no puede tener la relación de equivalente consigo misma. 
Por lo tanto, esta forma puede mostrar el valor de cualquier mercancía, menos de sí misma. Sin embargo, la forma equivalente es aún más intrincada que lo que hemos visto hasta el momento, y Marx desarrolla la argumentación de su análisis en los siguientes párrafos:

Pero en cuanto que la especie de mercancía levita toma en la expresión de valor el lugar del equivalente, su magnitud de valor no tiene ninguna expresión como tal magnitud de valor. Esta especie de mercancía no figura en la ecuación de valor más que como cantidad determinada de una $\operatorname{cosa}^{28}$. Por ejemplo: 40 codos de lino «valen» ¿qué? 2 levitas. Como la especie mercantil levita desempeña aquí el papel de equivalente, como el valor de uso levita funciona como cuerpo de valor respecto del lino, basta una determinada cantidad de levitas para expresar una determinada cantidad de valor de lino. Por eso dos levitas pueden expresar la magnitud de valor de 40 codos de lino, pero no pueden nunca expresar su propia magnitud de valor, la magnitud de valor de levitas (Marx, 1976, p. 64).

Figura 4. Forma Equivalente

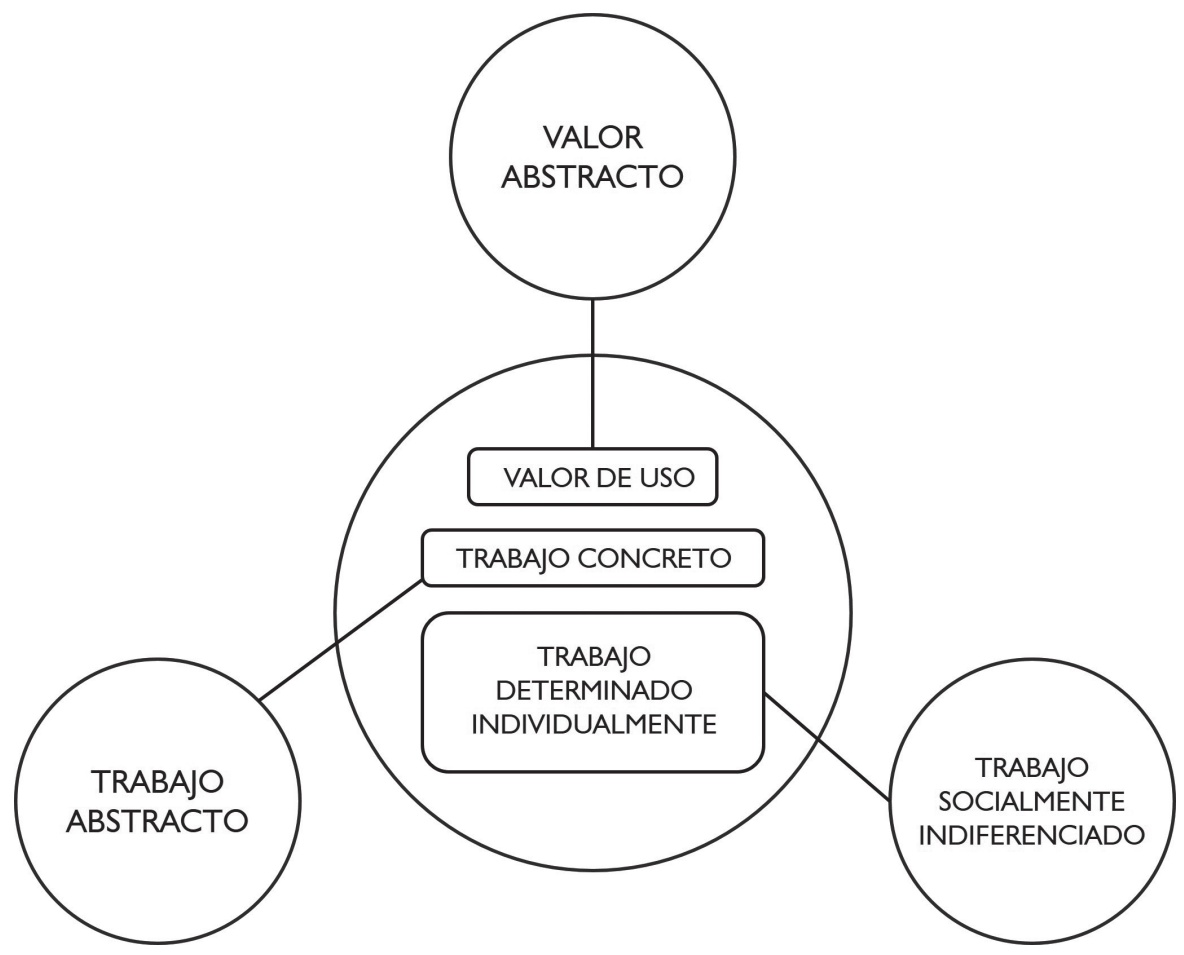

Fuente: Ideograma diseñado por el autor para visualizar el concepto desarrollado por Marx en Das Kapital

${ }^{28}$ Es decir: no como cantidad de valor, sino como cantidad de cosa concreta y útil [la nota es mía]. 
Forma equivalente: como se ve, los elementos del ámbito de lo abstracto (esferas satélite) deben remitirse al ámbito de lo concreto (esfera central) para "expresarse". Vemos, pues, que la forma equivalente no entraña determinación cuantitativa de valor alguno, sino que consiste únicamente en una cantidad concreta de algo que sirve para poner a este de manifiesto; que no puede expresar su propio valor, sino que únicamente puede poner de manifiesto el valor de lo que entra en esa relación con ella. Sobre este asunto, Marx desarrolla una argumentación que demuestra su capacidad de pensar dialécticamente:

La primera peculiaridad que llama la atención al considerar la forma de equivalente es esta: un valor de uso se convierte en forma de manifestación de su opuesto, el valor. La forma natural de la mercancía se convierte en forma de valor. Pero -nota bene- ese quidproquo no se produce para una mercancía B (levita, o trigo, o hierro, etc.) más que dentro de la relación de valor en que entra con ella otra mercancía cualquiera, A (lino, etc.), solo dentro de esa relación. Como ninguna mercancía se refiere a sí misma como equivalente, o sea, ninguna puede hacer de su propio pellejo natural expresión de su propio valor, tiene que referirse como a equivalente a otra mercancía, tiene que convertir el natural pellejo de otra mercancía en forma de valor suya propia (Marx, 1976, p. 65).

Ya hemos visto antes que la levita nos interesa no porque tenga valor (valor ya tiene el lino; si fuera valor lo que quisiéramos, no tendríamos ninguna necesidad de ir a cambiarlo) sino porque tiene la cualidad de ser útil como atuendo que nos permite asistir a determinadas reuniones sociales, en otras palabras, tiene valor de uso. Para poder conocer qué cantidad de valor "contiene" nuestro lino, debemos compararlo no con otra cantidad de valor, sino con la cantidad de una cosa que nos sirva para algo y que necesitemos o deseemos (vale decir, cambiamos valor abstracto por cosa útil). En este punto, Marx ofrece al lector de El Capital una analogía muy útil para ilustrar mejor el aludido quidproquo:

Nos ilustrará eso el ejemplo de una medida que conviene a los cuerpos de mercancías en cuanto cuerpos de mercancías, esto es, en cuanto valores de uso. Un pilón de azúcar, como es un cuerpo, gravita y, consiguientemente, tiene peso; pero no es posible percibir con la vista o con el tacto el peso de un pilón de azúcar. Tomamos, entonces, diversos trozos de hierro cuyo peso está determinado previamente. La forma corpórea del hierro tomada en sí misma no es en absoluto forma de manifestación de la gravedad, exactamente igual que ocurre con la del pilón de azúcar. A pesar de ello, para expresar el pilón de azúcar en cuanto grave le ponemos en una relación de peso con el hierro. En esta relación el hierro funciona como cuerpo que no representa absolutamente nada más que gravedad. Por lo tanto, las cantidades de hierro sirven de medida del peso del azúcar y no representan, respecto del cuerpo del azúcar, más que mera forma de la gravedad, forma de manifestación de la gravedad. El hierro no desempeña ese papel más que dentro de esta relación en la cual entra con él el azúcar 
o cualquier otro cuerpo cuyo peso se trate de averiguar. Si las dos cosas no fueran graves, no podrían entrar en esa relación ni, por lo tanto, podría la una servir de expresión de la gravedad de la otra. Cuando las ponemos ambas en la balanza, vemos efectivamente que son lo mismo en cuanto gravedad y, por lo tanto, que, en determinadas proporciones, son del mismo peso. Del mismo modo que el cuerpo férreo en cuanto medida de peso no representa respecto del pilón de azúcar más que gravedad, así también en nuestra expresión de valor el cuerpo de la levita no representa frente al lino más que valor. Pero con esto se acaba la analogía. En la expresión de peso del pilón de azúcar el hierro representa una propiedad natural común a ambos cuerpos, su gravedad; mientras que en la expresión de valor del lino la levita representa una propiedad sobrenatural de ambos: representa su valor, una cosa puramente social (1976, pp. 65-66).

Con este argumento Marx pone en evidencia el hecho de que no somos conscientes de que el valor es una propiedad social de sus portadores (las mercancías) y lo percibimos como una propiedad intrínseca de estas. La arquitectura alienada de nuestra mente proyecta sobre las cosas y las relaciones, entre estas, los a priori que convienen al caso. Nuestra relación alienada (a la que nos referíamos antes), con aquello que producimos, acarrea que las cosas que producimos se convierten en entes portadores de las cualidades y relaciones humanas mientras que los humanos somos relegados a meros intermediarios de las relaciones entre las cosas en las cuales nos hemos alienado.

Ya por el hecho de que la forma relativa de una mercancía — por ejemplo, del lino- expresa su valer como algo del todo distinto de su cuerpo y de sus propiedades — por ejemplo, como cosa igual a levitas-, esta expresión misma indica que está escondiendo una relación social. Y a la inversa por lo que hace a la forma de equivalente. Pues esta expresa precisamente que un cuerpo de mercancía, una levita, por ejemplo, la cosa tal cual es, expresa valor, es decir, posee por naturaleza forma de valor. Es verdad que esto solo vale dentro de la relación de valor en la cual la mercancía lino se refiere a la mercancía levita como a equivalente ${ }^{29}$. Pero como las propiedades de una cosa no nacen de su relación con otras, sino que en esta relación no hacen más que actuarse, la levita parece poseer por naturaleza su forma de equivalente, su propiedad de intercambiabilidad inmediata, exactamente igual que su propiedad de ser pesada o de dar calor. Aquí tiene su origen el carácter enigmático de la forma de equivalente, carácter que no salta a la embotada vista burguesa de los cultivadores de la economía política más que en el momento en que esa forma se les enfrenta, ya terminada, en el dinero. Entonces el economista intenta quitarse de encima el carácter

\footnotetext{
${ }^{29}$ Semejantes determinaciones de la reflexión* tienen siempre su peculiaridad. Tal hombre, por ejemplo, es rey por la única razón de que otros seres humanos se comportan respecto de él como súbditos. Ellos, a la inversa, creen que son súbditos porque el otro es rey. [*"Determinaciones de la reflexión" quiere decir conceptos fijos aplicados a las cosas para comprenderlas en una primera aproximación, prescindiendo de su movimiento, de su cambiar, de su relatividad, de su historia. La noción procede de la filosofía de Hegel—Nota de Marx-].
} 
místico del oro y de la plata mediante una explicación que consiste en deslizar bajo ellos mercancías menos esplendorosas y canturrear, con satisfacción constantemente renovada, el catálogo de todas las mercancías de a pie que en otros tiempos desempeñaron el papel de equivalente de mercancías. No se da cuenta siquiera de que ya la más sencilla expresión de valor, como 20 codos de lino $=1$ levita, plantea el enigma de la forma de equivalente ${ }^{30}$ (1976, p. 66).

Subrayemos la acusación de Marx a los economistas al final de la cita: no se dan cuenta siquiera de que ya la más sencilla expresión de valor, como 20 codos de lino $=1$ levita iplantea el enigma de la forma de equivalente! Es decir: todo lo que se ha venido argumentando hasta aquí, de lo que se esconde tras esa relación. Ahora se entiende perfectamente que tal acusación de Marx sea aplicable, también, a todos aquellos que sugieren saltarse el primer capítulo de Das Kapital, como el señor Althusser entre otros. Lo equivalente a este despropósito sería recomendar leer a Einstein saltándose la Teoría de la Relatividad o escuchar a Mozart omitiendo el Requiem en Re menor.

A través del hábito, de la cotidianeidad, la relación de cambio de la tela de lino por levitas convierte a estas en equivalentes naturales de aquella, de modo que la equivalencia deviene, "para nosotros", una propiedad natural de la levita y como tal la percibimos. La naturaleza alienada del asunto se pone de manifiesto en la paradoja de que la cualidad sirva para reflejar la cantidad; que aquello que en esa relación desempeña el papel de equivalente, es decir, el representante "oficial" del carácter útil y concreto de la plasmación del trabajo humano en su creación intervenga en esa relación como encarnación del trabajo abstracto, vacío de contenido. Como las paradojas a las que era sometida Alicia, la levita solamente puede estar al otro lado del espejo siendo y no siendo al mismo tiempo una levita: para que el valor de nuestra tela de lino se pueda ver reflejado en la levita como equivalente, el trabajo de sastrería de nuestro vecino debe despojarse de cualquier atributo que no sea su propiedad abstracta de ser trabajo humano en general. Así, pues, para expresar

[...] que el tejer constituye el valor del lino no en su concreta forma de trabajo textil, sino en su propiedad general de trabajo humano, se le enfrenta el trabajo de sastrería, el trabajo concreto que produce el equivalente del lino, como forma tangible de realización de trabajo abstractamente humano. Hay, pues, una segunda peculiaridad de la forma de equivalente: que en ella trabajo concreto se convierte en forma de manifestación de su opuesto, de trabajo abstractamente humano (Marx, 1976, p. 67).

Ahora, no obstante, observa Marx que:

\footnotetext{
${ }^{30}$ Una de las acepciones de "equivalente" es la expresión cuyas palabras son distintas de las de otra frase cualquiera, pero que tiene el mismo sentido.
} 


\begin{abstract}
En cuanto ese concreto trabajo de sastrería funciona como mera expresión de trabajo humano indiferente, posee la forma de igualdad con otro trabajo, el trabajo presente en el lino, aunque trabajo privado como todo otro trabajo productor de mercancías, es tanto, también trabajo en forma inmediatamente social. Precisamente por eso se representa en un producto inmediatamente intercambiable con otra mercancía. Es, pues, una tercera peculiaridad de la forma de equivalente el que trabajo privado se convierte en la forma de su opuesto, en trabajo en forma inmediatamente social (1976, p. 67).
\end{abstract}

En otras palabras: el hecho de que las levitas, producto de trabajo privado, sirven para expresar el valor de otras cosas — en el caso que nos ocupa muestran el de nuestro lino- las inviste de referentes del trabajo social inmediato.

Aristóteles era, para Marx, uno de los grandes pensadores de la historia; se refiere a él como al "gran investigador que analizó por vez primera la forma de valor" (1976, p. 67). De hecho, Aristóteles, en su Política (verba ex memoria) descubrió que la forma dinero no es más que un desarrollo de la forma simple de valor, y reparó en el hecho de que, para igualar entidades diferentes en la relación de intercambio, hay que referirlas a un tercer elemento. Sin embargo, Aristóteles no llegó a descubrir qué es lo que confiere el "don" de ser igualables a entidades distintas; la causa de esa limitación — sostiene Marx (loc cit) — radica en que en la sociedad griega no existía el trabajo tal como lo conocemos hoy en día: a saber, como actividad humana abstracta, sino que las diferentes actividades productivas de los griegos eran tareas concretas e irreducibles, por su propia naturaleza, a una generalización abstracta. La forma equivalente tiene, pues, tres particularidades que la caracterizan:

1. El valor abstracto, en general, vacío de todo contenido, se expresa a través de su contrario, el valor de uso;

2. el trabajo abstractamente humano, des-cualificado, que produce valor en general, tiene el modo de expresión en su contrario, el trabajo concreto, cualificado, que produce cosas concretas y útiles;

3. el trabajo indiferentemente social ${ }^{31}$ y alienado, integrado en la suma indiferenciada de los trabajos productores de valor "a secas", se manifiesta a través del trabajo individual, privado, cuyo producto es la mercancía concreta.

La religión, para poder adorar de modo "realista" a sus objetos de culto, necesita "encarnarlos" en íconos, pinturas y esculturas, haciéndolos, de paso, "tangibles" para los fieles; análogamente, los entes que residen en el mundo abstracto del valor necesitan manifestarse en objetos del mundo real para demostrar su existencia.

\footnotetext{
${ }^{31}$ Para el capital, lo social tan solo importa como ámbito de la organización de la producción y del consumo en aras de la reproducción de valor; el individuo, por tanto, únicamente interesa como factor de producción y consumo.
} 


\section{A modo de conclusión}

Uno de los objetivos principales del presente trabajo ha consistido en interpretar y desarrollar la parte de Das Kapital que versa sobre el análisis de la mercancía, para poner de manifiesto: la naturaleza densa, consistente y profunda de los contenidos; la importancia y la transcendencia filosóficas del concepto desarrollado por Marx de forma de valor, tanto en su planteamiento como en su análisis que desvela su dúplice carácter como forma relativa y forma equivalente.

Interpretando y extendiendo el análisis de Marx, se ha desvelado la naturaleza psicosocialmente esotérica de la mercancía. Del desarrollo de dicho análisis se ha inferido un hecho substancial que podríamos denominar: "el funcionamiento de la sociedad" o "el funcionamiento del sistema" está estrechamente vinculado a la estructura compleja e intrincada de la mercancía (concretamente, en la actualidad, en su forma completada: la forma dinero). Por "méritos propios" la mercancía se ha incardinado en el sistema de relaciones "materiales" y "espirituales" de la sociedad, siendo uno de los elementos fundamentales de la arquitectura de la alienación.

Se ha mencionado también el carácter contingente del soporte de la mercancía, para poner una analogía llamativa: el carácter de mercancía es como una patología cuyo virus transmisor puede contagiar a cualquier tipo de ente, sea material, espiritual o intangible. Y eso es así porque al capital, cuyo modo de organización es el que por desgracia rige las vidas de los habitantes del planeta Tierra, lo único que le importa es que la mercancía sea capaz de aumentar la cifra que da "sentido" a su existencia.

También hemos visto la naturaleza "subconsciente" de la mercancía. Su estructura funciona de modo oculto a nuestra percepción, porque pertenece al ámbito de lo constitutivo; de aquello a lo que nos referíamos con la expresión "el juego que siempre ya estamos jugando" y que, por tanto, está regido por las normas a priori y se halla subsumido en el contexto de lo que de antemano rige y regula nuestro comportamiento cotidiano y forma parte de la totalidad de lo consuetudinario, idiosincrásico e ideológico, es decir: de la alienación como sistema.

A través de la descripción del análisis de la mercancía, hemos puesto de manifiesto que esta célula del sistema capitalista — como la define Marx — no es un objeto cualquiera. Podríamos conceder que en cierto modo está "vivo", ya que posee propiedades sociales mediante las cuales mantiene complejas relaciones con el mundo del valor, que es el ámbito de lo social abstraído y cosificado. A través del análisis de la forma relativa, hemos desvelado la existencia de un valor "en potencia" y hemos observado que este valor, latente y contingente, solo se 
actualiza al reflejarse en algo necesario y tangible ${ }^{32}$ : el cuerpo de una mercancía, la cual, por otro lado, no puede ser la misma (ya que el valor solo puede ponerse de manifiesto, como ha quedado demostrado, a través de una mercancía distinta).

En el análisis de la forma equivalente se ha expuesto cómo aquel ámbito de lo abstracto, descalificado e indiferentemente social y alienado, únicamente puede evidenciar su existencia real cuando tiene frente a sí algo útil, concreto e individual —relativo a alguien — a través de lo cual manifiesta que existe (hágase hincapié en el prefijo del latín ex).

El desarrollo del análisis y la argumentación del mismo nos ha llevado al momentum; a la singularidad lógica (por su carácter lógicamente necesario) e histórica (porque marca un punto de inflexión; de no retorno en la historia) en que la forma equivalente se encarna en una mercancía cuyo valor de uso consiste en ser el representante oficial del valor; es en ese momento cuando al valor se le deja de exigir que se justifique como tal, bastándonos con una representación numérica del mismo. Este es pistoletazo de salida de la guerra sin cuartel del capital y para desencadenamiento de las pasiones más mezquinas que anidan en el pecho humano. La última forma en que se encarna el valor es la fantasmagórica forma dinero, verdadera tirana de nuestras conciencias. Aristóteles podría solemnemente echarnos en cara: "os previne".

\section{Referencias}

Althusser. L. (2010). Para leer El Capital. Madrid: Siglo XXI Editores.

Aristóteles (1987). Política. Madrid: Gredos.

Bertalanffy, L. V. (1976). Teoría General de Sistemas. Ciudad de México: Fondo de Cultura Económica.

Hegel, G. W. F. (1974). Ciencia de la Lógica. Buenos Aires: Solar-Hachette.

Marx, K. (1976). El Capital. Barcelona: Grijalbo.

Marx, K. (1977). Líneas fundamentales de la crítica de la economía política "Grundrisse". Barcelona: Grijalbo.

Soler Alomà, J. (2002). El concepte d'alienació en el pensament de Karl Marx. (Tesis de doctorado). Universidad de Barcelona, Barcelona, España.

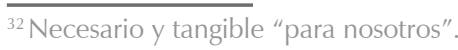


Soler Alomà, J. (2004). Sociedad y Alienación: vigencia de los planteamientos de Marx en el análisis del mundo actual. Ponencia presentada en el Congreso Internacional de Filosofía, La Habana, Cuba.

Stein, B. (26 de noviembre de 2006). Entrevista a Warren E. Buffett. New York Times.

Vernant, J. P. (1993). El hombre griego. Madrid. Alianza Editorial. 